\begin{tabular}{|c|c|}
\hline Title & $\begin{array}{l}\text { Photoelectrochemical Property of Tungsten Oxide Films of V ertically A ligned Flakes for V isible Light-Induced W ater } \\
\text { Oxidation }\end{array}$ \\
\hline Author(s) & A mano, Fumiaki; Li, Ding; Ohtani, Bunsho \\
\hline Citation & $\begin{array}{l}\text { Journal of the Electrochemical Society, 158(2), K42-K46 } \\
\text { https://doi.org/10.1149/1.3525624 }\end{array}$ \\
\hline Issue Date & 2011 \\
\hline Doc URL & http:/hdl. handle.net/2115/45357 \\
\hline Rights & $\begin{array}{l}\text { () The Electrochemical Society, Inc. 2011. All rights reserved. Except as provided under U.S. copyright law, this work } \\
\text { may not be reproduced, resold, distributed, or modified without the express permission of The Electrochemical Society } \\
\text { (ECS). The archival version of this work was published in J. Electrochem. Soc., 158(2), pp. K42-K } 46 \text { (2011). }\end{array}$ \\
\hline Type & article \\
\hline File Information & JES158-2_K42-K46.pdf \\
\hline
\end{tabular}

Instructions for use 


\title{
(4hS) \\ Photoelectrochemical Property of Tungsten Oxide Films of Vertically Aligned Flakes for Visible-Light-Induced Water Oxidation
}

\author{
Fumiaki Amano, ${ }^{\mathrm{a}, \mathrm{b}, *, \mathrm{z}}$ Ding Li, ${ }^{\mathrm{b}}$ and Bunsho Ohtani ${ }^{\mathrm{a}, \mathrm{b}}$ \\ ${ }^{a}$ Catalysis Research Center, Hokkaido University, Sapporo 001-0021, Japan \\ ${ }^{b}$ Graduate School of Environmental Science, Hokkaido University, Sapporo 060-0810, Japan
}

\begin{abstract}
A vertically arrayed flake film, "flake-wall film," of monoclinic tungsten oxide $\left(\mathrm{WO}_{3}\right)$ was prepared on a transparent conductive glass by controlling anisotropic crystal growth and self-arrayed growth of $\mathrm{WO}_{3}$ hydrate with a layered crystal structure. The $\mathrm{WO}_{3}$ flake-wall film exhibited superior performance for photoelectrochemical water oxidation under visible-light irradiation compared to that of a film consisting of horizontally laminated $\mathrm{WO}_{3}$ flakes. The small differences between photocurrents under front-side irradiation and back-side irradiation and between photocurrents in the absence and the presence of methanol indicate the excellent electron transport property and long photogenerated carrier lifetime in the flake-wall film. (c) 2010 The Electrochemical Society. [DOI: 10.1149/1.3525624] All rights reserved.
\end{abstract}

Manuscript submitted August 18, 2010; revised manuscript received November 15, 2010. Published December 20, 2010. This was Paper 1646 presented at the Vancouver, Canada, Meeting of the Society, April 25-30, 2010.

Development of highly efficient semiconductor electrodes and photocatalysts is one of the most important subjects for solar-energy conversion and environmental purification. Hydrogen production by water splitting using a renewable energy, solar light, is a key technology for further fabrication of a hydrogen economy to achieve low-carbon society. ${ }^{1-3}$ Photoelectrochemical oxidation of water into oxygen is induced by photogenerated valence-band holes of n-type metal-oxide films under anodic polarization. High incident photonto-current conversion efficiency has been reported for nanocrystalline films of tungsten oxide $\left(\mathrm{WO}_{3}\right)$ with a large interface of semiconductor/liquid. ${ }^{4-11}$ The nanocrystalline films require thickness of several micrometers to maximize absorption of incident photons, while an increase in the thickness would increase the density of grain boundaries, resulting in the retardation of electron transport to the back-contacted conductive substrate due to resistance (Fig. 1a). ${ }^{10,12}$ The grain boundaries also seem to act as recombination centers to reduce the lifetime of photoexcited carriers. Conversely, films of platelike crystallites vertically arrayed to the substrate are expected to exhibit photoelectrochemical performance superior to that of films with a large number of grain boundaries (Fig. 1b). Recently, we have fabricated $\mathrm{WO}_{3}$ films consisting of crystalline flakes vertically arrayed to the substrate (flake-wall films) by controlling the anisotropic crystal growth of tungsten oxide monohydrate $\left(\mathrm{WO}_{3} \cdot \mathrm{H}_{2} \mathrm{O}\right)$, followed by calcination. ${ }^{13}$ It has been reported that the photoelectrochemical performance of the vertically arrayed crystalline structures to the conductive substrates is relative to that of the particulate nanocrystalline structures. ${ }^{12,14-16}$ However, the systematic comparisons of the properties of the semiconductor electrode with different orientations of the same crystalline structure have not been performed. In the present study, we investigated the photoelectrochemical properties of the flake-wall film and film consisting of horizontally laminated flakes (flake-laminate films) for oxidation of water ${ }^{17}$ and methanol.

\section{Experimental}

Preparation of tungsten oxide films. - Tin-oxide $\left(\mathrm{SnO}_{2}\right)$-deposited glass was used for a transparent conductive substrate and was covered with a nanocrystalline $\mathrm{WO}_{3}$ thin film using a colloidal solution of tungstic acid. ${ }^{5,6}$ The colloidal solution was obtained by passing an aqueous solution of sodium tungstate through a column packed with a proton exchange resin (Dowex, Aldrich 50WX2, 100$200 \mathrm{mesh}$ ), followed by collection in ethanol and evaporation to give a solution with a concentration of ca. $1.0 \mathrm{~mol} \mathrm{l}^{-1}$. After addi-

\footnotetext{
Electrochemical Society Active Member.
}

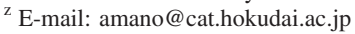

tion of polyethylene glycol 300 (Wako Pure Chemical Industries), the viscous colloidal solution was coated on a conductive glass by a paste-squeegee method and annealed at $773 \mathrm{~K}$ for $30 \mathrm{~min}$.

Deposition of $\mathrm{WO}_{3} \cdot \mathrm{H}_{2} \mathrm{O}$ crystallites was performed using a newly developed solvothermal method. ${ }^{13}$ Tungsten chloride ( $\mathrm{WCl}_{6}$, $2 \mathrm{mmol}$ ) was dissolved in $70 \mathrm{~mL}$ ethanol in a globe box filled with dry air to prevent hydrolysis by atmospheric humidity. The substrate covered with a nanocrystalline $\mathrm{WO}_{3}$ film $\left(5.25 \mathrm{~cm}^{2}\right)$ was immersed in the ethanol solution of $\mathrm{WCl}_{6}$ and heated in a $100 \mathrm{~mL}$ Teflon-lined autoclave at $373 \mathrm{~K}$ for $20 \mathrm{~h}$. The obtained film was washed with water, dried at $393 \mathrm{~K}$, and calcined at $773 \mathrm{~K}$ for $2 \mathrm{~h}$.

Flake-laminate films were prepared by the paste-squeegee method using $\mathrm{WO}_{3} \cdot \mathrm{H}_{2} \mathrm{O}$ precipitates crystallized during the solvothermal reaction for the flake-wall film preparation. The paste obtained by mixing crystalline powders, pure water, acethylacetone, and surfactant Toriton X-100 (Aldrich) in a mortar was coated on the $\mathrm{SnO}_{2}$ glass or nanocrystalline $\mathrm{WO}_{3}$ film, followed by calcination at $773 \mathrm{~K}$ for $2 \mathrm{~h}$.

Photoelectrochemical reaction.- The photoelectrochemical properties of the prepared films were investigated using a threeelectrode system in a cylindrical glass vessel at room temperature. A platinum wire was used as a counter electrode. A silver/silver chloride $(\mathrm{Ag} / \mathrm{AgCl})$ electrode in an aqueous solution of $3 \mathrm{~mol} \mathrm{l}^{-1}$ sodium chloride $(+0.209 \mathrm{~V}$ vs standard hydrogen electrode) was used as a reference electrode. An aqueous solution of $0.1 \mathrm{~mol} \mathrm{l}^{-1}$ sodium sulfate $\left(\mathrm{Na}_{2} \mathrm{SO}_{4}\right)$ was used as a supporting electrolyte. An aqueous solution of $10 \mathrm{vol} \%$ methanol with $0.1 \mathrm{~mol} \mathrm{l}^{-1} \mathrm{Na}_{2} \mathrm{SO}_{4}$ was used for the photoelectrochemical oxidation of methanol. The electrode potential was swept in the anodic direction at a rate of $50 \mathrm{mV} \mathrm{s}^{-1}$ using a potentiostat (Princeton Applied Research, Oak Ridge PARSTAT 2263). Visible-light irradiation ( $>400 \mathrm{~nm}$ ) was performed using a $300 \mathrm{~W}$ xenon arc lamp equipped with a cutoff filter (Asahi Techno Glass, L42, Tokyo, Japan) under magnetic stirring.

Characterization.- Scanning electron microscopic (SEM) images were obtained by a JEOL, Tokyo, Japan, JSM-7400F. Diffuse transmission spectra were recorded by a JASCO, Tokyo, Japan, V-670 spectrometer equipped with a PIN-757, JASCO integrating sphere. X-ray diffraction (XRD) patterns were recorded on a Rigaku, Tokyo, Japan, RINT ultima diffractometer with $\mathrm{Cu} \mathrm{K} \alpha$ radiation.

\section{Results and Discussion}

Flake-wall film.- XRD pattern and SEM images of the precipitates generated by solvothermal reaction of $\mathrm{WCl}_{6}$ in ethanol solution are shown in Fig. 2 and 3, respectively. The particles exhibited XRD 


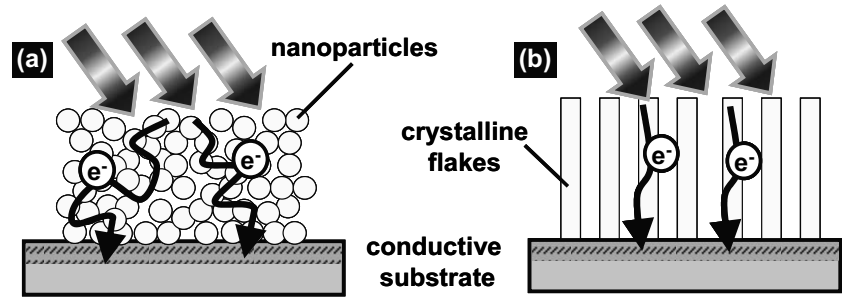

Figure 1. Schematic illustration of photoexcited electron transport in (a) a nanocrystalline film and (b) a vertically arrayed crystalline film.

pattern attributable to orthorhombic $\mathrm{WO}_{3} \cdot \mathrm{H}_{2} \mathrm{O}$ (JCPDS card no. 430679) with a layered crystal structure. ${ }^{18}$ The morphology of particles was found to be micrometer-sized aggregates composed of many crystalline flakes. Some precipitates deposited on the wall of the Teflon-lined autoclave showed assemblies of crystalline flakes (Fig. $3 b)$. This self-arrayed crystal growth would occur after heterogeneous nucleation on the wall.

Based on the findings of production of flake arrays, we tried to control the self-arrayed anisotropic crystal growth of $\mathrm{WO}_{3} \cdot \mathrm{H}_{2} \mathrm{O}$ on a transparent conductive substrate. Covering with a nanocrystalline $\mathrm{WO}_{3}$ film was found to be essential for fabricating a vertically oriented flake film. No appreciable deposition was observed on a substrate in the absence of a nanocrystalline $\mathrm{WO}_{3}$ film, which was assumed to be a base layer for heterogeneous nucleation and adhesion of crystalline $\mathrm{WO}_{3} \cdot \mathrm{H}_{2} \mathrm{O}$ on the substrate. It should be noted that the base layer plays a role of protection of the substrate from damage by strong acidity of the solution. The thus-obtained film was calcined in air at $773 \mathrm{~K}$ for $2 \mathrm{~h}$. Figure 4 shows side-view and top-view SEM images of the prepared film. Crystalline flakes with heights of several micrometers were seen to be self-arrayed and

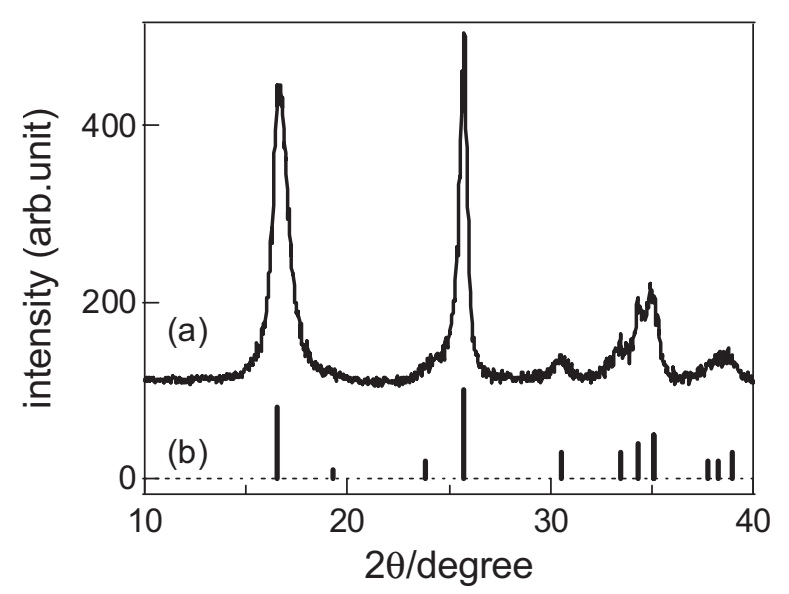

Figure 2. XRD patterns of (a) particles generated by solvothermal reaction and (b) $\mathrm{WO}_{3} \cdot \mathrm{H}_{2} \mathrm{O}$ (JCPDS card no. 43-0679)
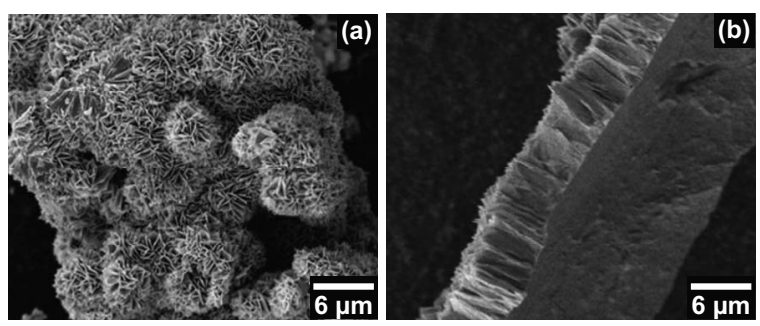

Figure 3. SEM images of (a) particles of flake assembly collected from the bottom and (b) a part of flake assembly detached from the wall of the Teflonlined autoclave after solvothermal reaction.

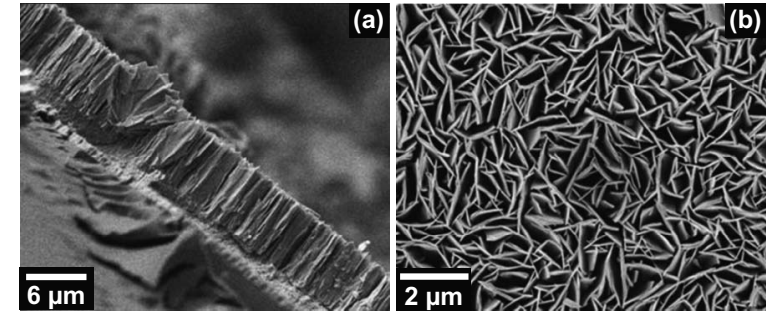

Figure 4. (a) Side-view and (b) top-view images of a flake-wall film.

normal to the substrate covered by a nanocrystalline $\mathrm{WO}_{3}$ film with a height of ca. $1 \mu \mathrm{m}$. This film was called as a $\mathrm{WO}_{3}$ flake-wall film because the crystalline flakes were vertically standing on the substrate like a wall. XRD measurement suggests that most of the (110) planes of monoclinic $\mathrm{WO}_{3}$ were parallel to the substrate. ${ }^{13}$

Flake-laminate film.- Figure 5 shows top-view SEM images of another film prepared by the paste-squeegee method using $\mathrm{WO}_{3} \cdot \mathrm{H}_{2} \mathrm{O}$ precipitates and subsequent calcination. The crystalline flakes were found to be piled up on the substrate. Figure 6 shows XRD patterns of the film and the calcined powder of $\mathrm{WO}_{3} \cdot \mathrm{H}_{2} \mathrm{O}$ precipitates. Both patterns could be assigned to monoclinic $\mathrm{WO}_{3}$. The peak intensity of 002 diffraction for the film was found to be much higher than that for the particles. This indicates that the (001) planes of monoclinic $\mathrm{WO}_{3}$ have a tendency to be parallel to the substrate. Considering the preferential orientation of the (110) planes parallel to the substrate in the case of a flake-wall film, ${ }^{13}$ we

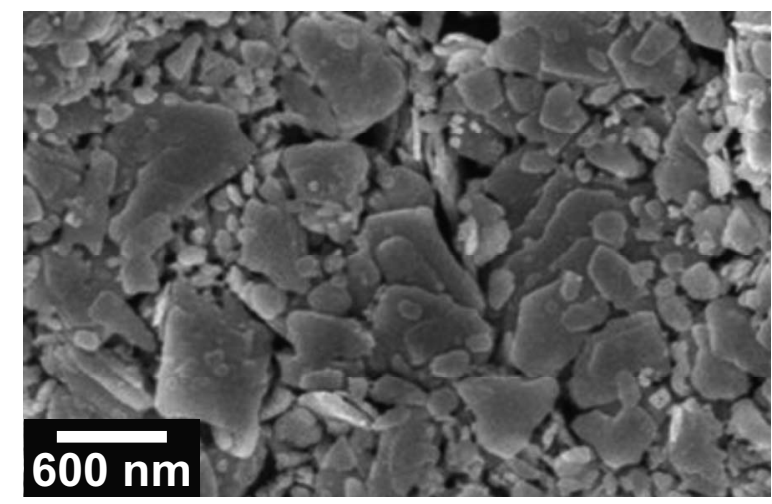

Figure 5. Top-view SEM images of a flake-laminate film.

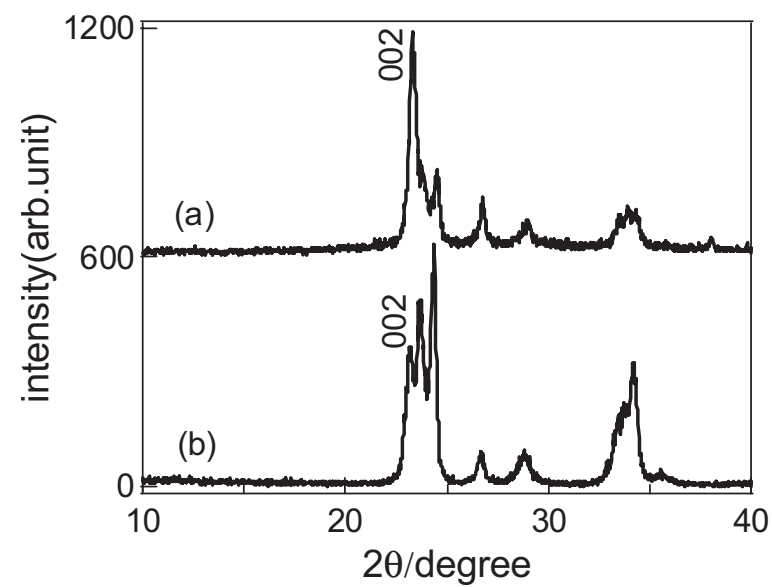

Figure 6. XRD patterns of (a) a flake-laminate film on $\mathrm{SnO}_{2}$ glass and (b) $\mathrm{WO}_{3}$ particles prepared by calcination of $\mathrm{WO}_{3} \cdot \mathrm{H}_{2} \mathrm{O}$ particles. 


\begin{tabular}{cccc}
\hline \multicolumn{2}{c}{ Table I. Amount of $\mathrm{WO}_{\mathbf{3}}$ on the films. } \\
$\begin{array}{c}\text { Weight of nanocrystalline } \\
\mathrm{WO}_{3} \text { as a base layer } \\
(\mathrm{mg})\end{array}$ & $\begin{array}{c}\text { Weight of } \\
\mathrm{WO}_{3} \text { flakes } \\
(\mathrm{mg})\end{array}$ & $\begin{array}{c}\text { Total weight of } \\
\mathrm{WO}_{3} \\
(\mathrm{mg})\end{array}$ \\
\hline Sample & 2.1 & 6.5 & 8.6 \\
flake-wall film & 2.2 & 6.0 & 8.2
\end{tabular}

concluded that the largely exposed facet of crystalline flakes was $\mathrm{WO}_{3}$ (001). This film, composed of horizontally laminated flakes, was denoted as a flake-laminate film.

Photoelectrochemical properties.-Photoelectrochemical water oxidation was performed in an aqueous solution of $0.1 \mathrm{~mol} \mathrm{l}^{-1}$ $\mathrm{Na}_{2} \mathrm{SO}_{4}$ under visible-light irradiation. In order to compare the photoelectrochemical properties of flake-wall and flake-laminate films, we prepared films with similar weights of $\mathrm{WO}_{3}$ (see Table I). Because a base layer of nanocrystalline film is necessary for the fabrication of a flake-wall film, the flake-laminate film was prepared on the nanocrystalline film deposited on the $\mathrm{SnO}_{2}$ glass. The amounts of nanocrystalline $\mathrm{WO}_{3}$ (and total amounts of $\mathrm{WO}_{3}$ ) in those films were adjusted to similar weights.

Figure 7 shows ultraviolet-visible (UV-vis) diffuse transmittance spectra of those films. The photoabsorption edges were located at around $470 \mathrm{~nm}$. Transmittance at a longer wavelength of the flake-wall film was higher than that of the laminate film, suggesting higher transparency of the flake-wall film. The transmittance of $\mathrm{SnO}_{2}$ glass at this region was ca. $80 \%$ (data not shown). The transmittances of both films were dependent on the direction of incident light. Transmittance under the condition of back-side incidence through the transparent conductive glass was higher than that under the condition of front-side incidence through crystalline flakes. In the case of back-side incidence, the nanocrystalline film as a base layer might play the role of an antireflecting layer to diffuse light, which comes through the transparent conductive glass.

Figure 8x shows potential-current curves for water oxidation under back-side irradiation through the transparent conductive substrate. The photocurrent of the flake-laminate film was relatively small and quickly became saturated at a low anodic potential (ca. $0.6 \mathrm{~V}$ vs $\mathrm{Ag} / \mathrm{AgCl}$ ) compared to that of the flake-wall film. The saturated photocurrent density of the flake-wall films was much higher than that of the flake-laminate film. For the condition of front-side irradiation through the $\mathrm{WO}_{3}$ layer, the photocurrent of the flake-laminate film was much smaller than that of the flake-wall film. The ratios of photocurrent density by front-side irradiation to that by back-side irradiation, analysis of which has been employed

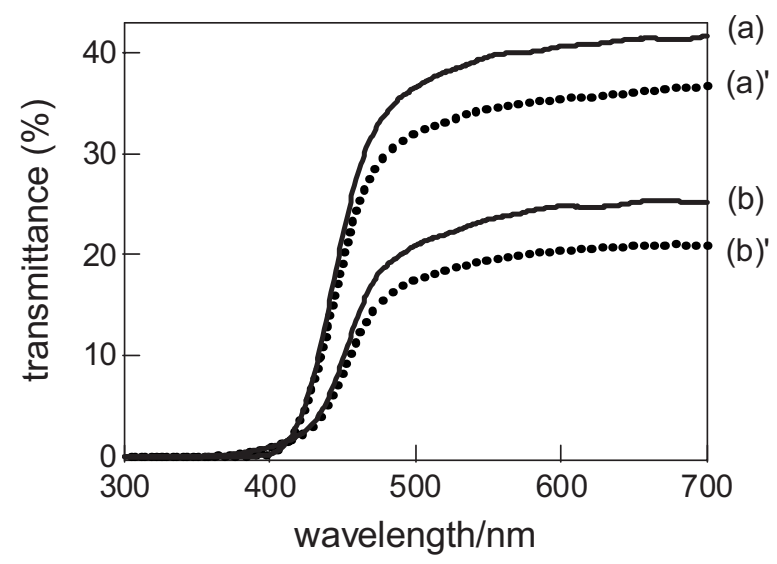

Figure 7. UV-vis diffuse transmittance spectra of (a) a flake-wall film and (b) a flake-laminate film. The films were illuminated from (solid curve) the back side and (dotted curve) the front side.
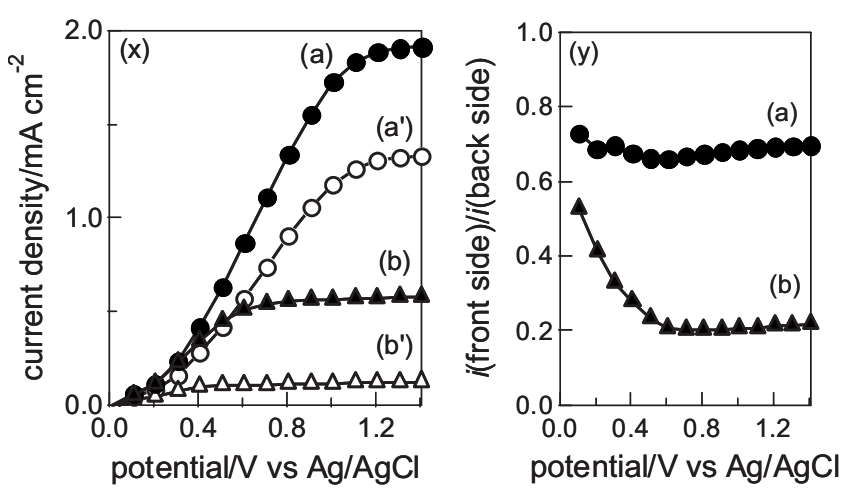

Figure 8. (x) Current-potential plots for (a) a flake-wall film and (b) a flake-laminate film in an aqueous solution of $0.1 \mathrm{~mol} \mathrm{l}^{-1} \mathrm{Na}_{2} \mathrm{SO}_{4}$ under visible-light irradiation from the back side and (plots of symbols with prime) from the front side. (y) Ratio of the photocurrent density by front-side irradiation to that by back-side irradiation.

in determining electron diffusion length in dye-sensitized solar cells and semiconductor electrodes, ${ }^{4,19,20}$ were plotted against the applied potential in Fig. 8y. The ratio was found to be 0.7 for the flake-wall film and 0.2 for the flake-laminate film at sufficiently high anodic polarization. This dependence of photocurrents on illumination direction indicates the presence of photoexcited carrier recombination during electron transport to the back-contacted conductive substrate. Most of the photoexcited electrons generated near the front side are not transported to the back-contacted substrate in the flake-laminate film with a high density of grain boundaries (Fig. 9b). Conversely, efficient transportation of photoexcited electrons would be achieved in the flake-wall films (Fig. 9a). The crystallinities of flakes seem to be similar in the two films because the conditions for growth of $\mathrm{WO}_{3} \cdot \mathrm{H}_{2} \mathrm{O}$ flakes and the calcination conditions were the same. Therefore, the difference in transport of photoexcited electrons would be only due to the orientation of the flakelike crystalline nanostructure to the substrate. The electron diffusion length analyzed from the ratio of 0.7 using the method developed by Wang et al. ${ }^{4}$ was found to be longer than $5 \mu \mathrm{m}$, which is the average thickness of the flake-wall film. It is concluded that the high efficiency of a flake-wall film for photoelectrochemical oxidation of water is probably due to the long electron diffusion length and the low density of grain boundaries in the electron transport direction.

Figure 10 shows potential-current curves for the oxidation of methanol under back-side irradiation and front-side irradiation. By adding methanol as a strong electron donor, the photocurrent onset potentials of both films were shifted to cathodic direction by ca. $0.2 \mathrm{~V}$ and the potentials to reach saturated photocurrent were shifted to anodic direction. For the flake-wall film, the photocurrent density was almost proportionally increased with an increase in the applied potential in the region of $0.0-1.4 \mathrm{~V}$ vs $\mathrm{Ag} / \mathrm{AgCl}$. This indicates that the photocurrent saturation observed for water oxidation by flakewall film is due to the low rate of surface reaction of photogenerated holes with water compared to that with methanol. It has been reported that the reaction rate of photogenerated hole with methanol,

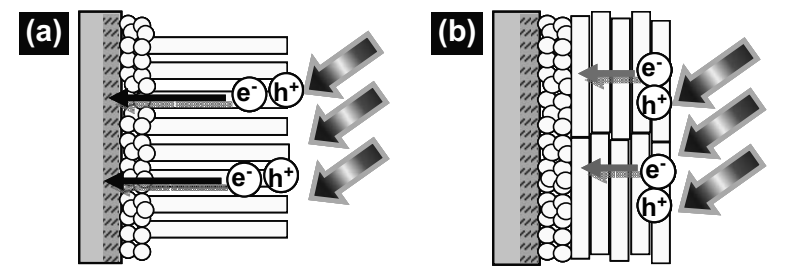

Figure 9. Schematic illustration of photoexcited electron transport in (a) a flake-wall film and in (b) a flake-laminate film under front-side irradiation. 

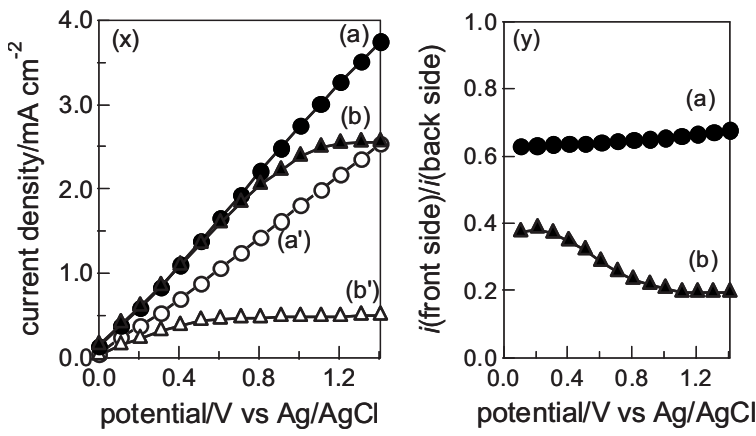

Figure 10. (x) Current-potential plots for (a) a flake-wall film and (b) a flake-laminate film in an aqueous solution of $10 \mathrm{vol} \%$ methanol with $0.1 \mathrm{~mol} \mathrm{l}^{-1} \mathrm{Na}_{2} \mathrm{SO}_{4}$ under visible-light irradiation from the back side and (plots of symbols with prime) from the front side. (y) Ratio of the photocurrent density by front-side irradiation to that by back-side irradiation.

$<1 \mathrm{~ns}$, is much faster than that with water, $<2 \mu \mathrm{s}$, for titanium(IV) oxide photocatalysts. ${ }^{21-23}$ Although the lifetime of positive holes is elongated with an increase in the anodic polarization, the time constant is not sufficient to induce water oxidation at the upper limit of photocurrent density. As shown in Fig. 10y, the ratios of photocurrent density by front-side irradiation to that by back-side irradiation were similar to the results in the absence of methanol at sufficiently high anodic polarization.

Figure 11 shows the ratio of photocurrent density for methanol oxidation to that for water oxidation. The ratio of the flake-wall film was ca. 2 at applied potentials more positive than $0.5 \mathrm{~V}$ vs $\mathrm{Ag} / \mathrm{AgCl}$. It is well known that hydroxymethyl radical $\left(\mathrm{CH}_{2} \mathrm{OH} \cdot\right)$, which is formed by direct hole transfer to methanol, exhibits large negative redox potential to induce one electron transfer to the conduction band of semiconductor electrodes without back-electron transfer. ${ }^{6,24}$ Therefore, the photocurrent is increased by two times by the addition of methanol, if the efficiencies of holes to react with water and methanol are the same and the efficiency of one electron transfer from $\mathrm{CH}_{2} \mathrm{OH}$. to the conduction band of $\mathrm{WO}_{3}$ is $100 \%$. In these experiments, the photoelectrochemical reaction was performed under air, so that some radicals could react with molecular oxygen. Therefore, we cannot simply classify the origin of ca. two-times enhancement for the flake-wall film by methanol addition to socalled "current doubling" effect. However, it is concluded that the difference in the reaction rate of holes with water and methanol is relatively small in the case of flake-wall films. Conversely, photocurrent for the flake-laminate film was enhanced by three to four times in the presence of methanol. Because this enhancement ratio

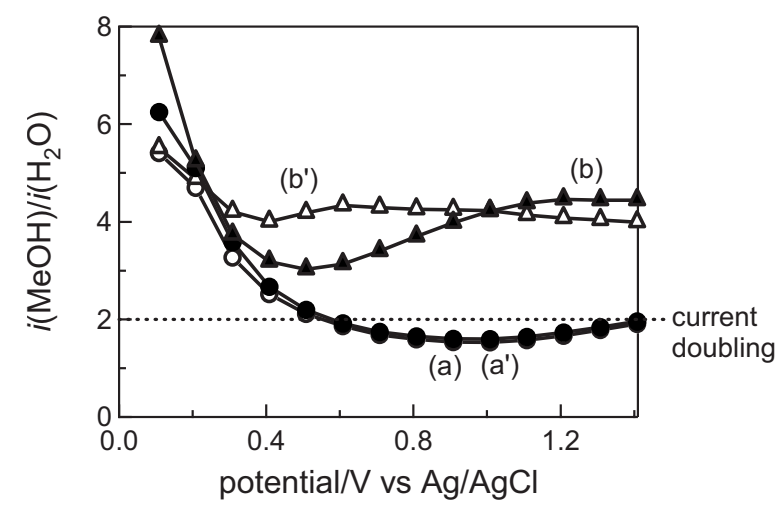

Figure 11. Ratio of the photocurrent density in the presence of methanol to that in the absence of methanol for (a) a flake-wall film and (b) a flakelaminate film under visible-light irradiation from the back side and (plots of symbols with prime) from the front side.

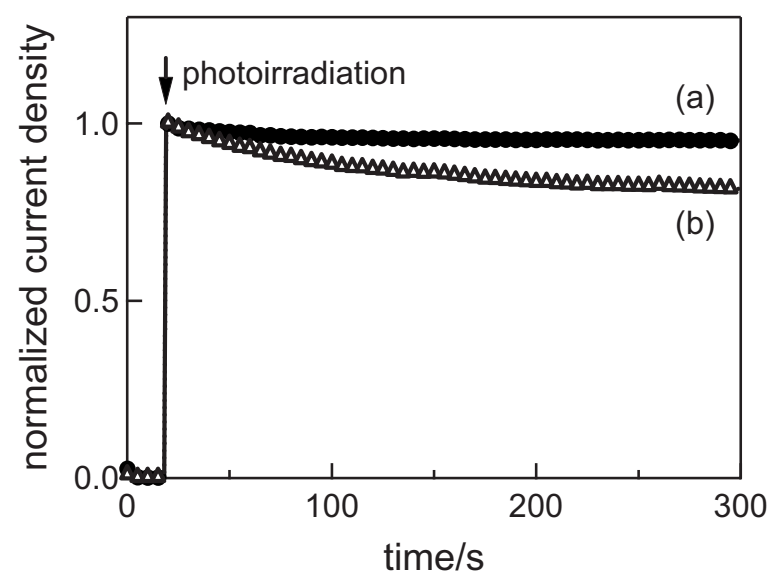

Figure 12. Current-time plots for (a) a flake-wall film and (b) a flakelaminate film in an aqueous solution of $10 \mathrm{vol} \%$ methanol with $0.1 \mathrm{~mol}^{-1}$ $\mathrm{Na}_{2} \mathrm{SO}_{4}$ under visible-light irradiation from the back side. The applied potential was kept at $+1.2 \mathrm{~V}$ vs $\mathrm{Ag} / \mathrm{AgCl}$.

cannot be explained only by current doubling, the reaction rate of holes with water is found to be much lower than that with methanol for the flake-laminate film. Although the ratio of photocurrent enhancement for the flake-wall film was not dependent on the direction of photoirradiation, the ratio for the flake-laminate film depends on the incident direction. The ratio was ca. 3 for back-side irradiation and 4 for front-side irradiation at around $0.5 \mathrm{~V}$ vs $\mathrm{Ag} / \mathrm{AgCl}$. Because the electrons excited near the substrate can transport to the back-contacted substrate at moderate applied potential, e.g., ca. $0.5 \mathrm{~V}$ vs $\mathrm{Ag} / \mathrm{AgCl}$, the lifetime of holes generated by back-side irradiation would be longer than that by front-side irradiation, in which most of the photoexcited electrons generated far from the conductive substrate. Based on the above consideration, the lifetimes of holes in flake-wall films are considered to be long enough to induce water oxidation under sufficiently anodic polarization and to be constant throughout the film due to the high electron transport ability.

Figure 12 shows current-time plots of the flake-wall film and the flake-laminate film for methanol oxidation under visible-light irradiation with stirring. The normalized photocurrent for the flakelaminate film gradually decreased with time of photoirradiation, contrary to the case for the flake-wall film. This decrease was not due to damage of the film, because the photocurrent was recovered by washing the used film by pure water. Considering the difference in the hierarchical structure of films, this decrease might be related to the diffusion rate of methanol in the films because the flake-wall film exhibits large void space between the crystalline flakes to diffuse reactant molecules.

\section{Conclusions}

$\mathrm{WO}_{3}$ flake-wall films exhibited photoelectrochemical efficiency higher than that of flake-laminate films for water oxidation. Short lifetime of photogenerated carriers in flake-laminate films even at anodic polarization was suggested by the results that the photocurrent was enhanced by adding methanol by more than four times. The less electron transport property of flake-laminate films was also suggested by the significant dependence on the photoirradiation side. Because the crystallinity of flakes seems to be similar between flake-wall films and flake-laminate films, the difference in the photoelectrochemical property would be due to the orientation of platelike crystallites to the substrate; the flake-wall film exhibits a lower density of grain boundaries into the electron transport direction, e.g., low density of recombination centers and high efficiency of electron transport. This would be the reason for the higher efficiency for photoelectrochemical oxidation of water compared to films with a high density of grain boundaries. Flake-wall films also show stable 
photocurrent during the photoelectrochemical oxidation of methanol probably due to the high porosity to diffuse reactant molecules. It is concluded that the control of vertically arrayed crystalline structures is a promising way to fabricate highly efficient semiconductor electrodes for chemical conversions under solar light.

\section{Acknowledgments}

This work was supported in part by the Global COE Program (Project no. B01: Catalysis as the Basis for Innovation in Materials Science) from the Ministry of Education, Culture, Sports, Science, and Technology, Japan (MEXT). F.A. is grateful to Nissan Science Foundation, Japan for financial support. SEM measurements were supported by Hokkaido Innovation through Nanotechnology Support (HINTS) of MEXT. article.

Hokkaido University assisted in meeting the publication costs of this

\section{References}

1. A. Kudo and Y. Miseki, Chem. Soc. Rev., 38, 253 (2009).

2. K. Maeda and K. Domen, J. Phys. Chem. Lett., 1, 2655 (2010).

3. Y. Miseki, H. Kusama, H. Sugihara, and K. Sayama, J. Phys. Chem. Lett., 1, 1196 (2010).

4. H. L. Wang, T. Lindgren, J. J. He, A. Hagfeldt, and S. E. Lindquist, J. Phys. Chem $B, 104,5686(2000)$.

5. C. Santato, M. Odziemkowski, M. Ulmann, and J. Augustynski, J. Am. Chem. Soc., 123, 10639 (2001)
6. C. Santato, M. Ulmann, and J. Augustynski, J. Phys. Chem. B, 105, 936 (2001). 7. B. Yang, Y. J. Zhang, E. Drabarek, P. R. F. Barnes, and V. Luca, Chem Mater, 19, 5664 (2007).

8. B. Yang, P. R. F. Barnes, W. Bertram, and V. Luca, J. Mater. Chem., 17, 2722 (2007).

9. M. Yagi, S. Maruyama, K. Sone, K. Nagai, and T. Norimatsu, J. Solid State Chem., 181, 175 (2008)

10. N. S. Gaikwad, G. Waldner, A. Bruger, A. Belaidi, S. M. Chaqour, and M. Neumann-Spallart, J. Electrochem. Soc., 152, G411 (2005)

11. S. Berger, H. Tsuchiya, A. Ghicov, and P. Schmuki, Appl. Phys. Lett., 88, 203119 (2006).

12. E. Thimsen, N. Rastgar, and P. Biswas, J. Phys. Chem. C, 112, 4134 (2008).

13. F. Amano, D. Li, and B. Ohtani, Chem. Commun. (Cambridge), 46, 2769 (2010).

14. N. Beermann, L. Vayssieres, S. E. Lindquist, and A. Hagfeldt, J. Electrochem. Soc 147, $2456(2000)$

15. M. Law, L. E. Greene, J. C. Johnson, R. Saykally, and P. D. Yang, Nature Mater, 4, 455 (2005).

16. S. K. Mohapatra, S. E. John, S. Banerjee, and M. Misra, Chem. Mater, 21, 3048 (2009).

17. F. Amano, D. Li, and B. Ohtani, ECS Trans., 28(17), 127 (2010).

18. J. T. Szymanski and A. C. Roberts, Can. Mineral., 22, 681 (1984)

19. J. Villanueva-Cab, H. X. Wang, G. Oskam, and L. M. Peter, J. Phys. Chem. Lett., 1, 748 (2010).

20. W. H. Leng, P. R. F. Barnes, M. Juozapavicius, B. C. O'Regan, and J. R. Durrant, J. Phys. Chem. Lett., 1, 967 (2010).

21. A. Yamakata, T. Ishibashi, and H. Onishi, J. Phys. Chem. B, 106, 9122 (2002).

22. A. Yamakata, T. Ishibashi, and H. Onishi, J. Mol. Catal. A: Chem., 199, 85 (2003).

23. Y. Tamaki, A. Furube, M. Murai, K. Hara, R. Katoh, and M. Tachiya, J. Am. Chem. Soc., 128, 416 (2006)

24. L. M. Peter, Chem. Rev., 90, 753 (1990). 